Southern Methodist University

SMU Scholar

Fondren Library Research

Fondren Library

Winter 2015

\title{
Marketing Finding Aids on Social Media: What Worked and What Didn't Work
}

\author{
Felicia Williamson \\ Dallas Holocaust Museum, fwilliamson@dallasholocaustmuseum.org \\ Scott Vieira \\ Rice University, svieira@rice.edu \\ James Williamson \\ Southern Methodist University, jdwilliamson@mail.smu.edu
}

Follow this and additional works at: https://scholar.smu.edu/libraries_cul_research

Part of the Archival Science Commons

\section{Recommended Citation \\ Williamson, Felicia; Vieira, Scott; and Williamson, James, "Marketing Finding Aids on Social Media: What Worked and What Didn't Work" (2015). Fondren Library Research. 15. \\ https://scholar.smu.edu/libraries_cul_research/15 \\ This document is brought to you for free and open access by the Fondren Library at SMU Scholar. It has been accepted for inclusion in Fondren Library Research by an authorized administrator of SMU Scholar. For more information, please visit http://digitalrepository.smu.edu.}




\title{
Marketing Finding Aids on Social Media: What Worked and What Didn't Work
}

\author{
Felicia Williamson, Scott Vieira, and James Williamson
}

\begin{abstract}
Sam Houston State University's Special Collections (SHSU) needed a way to expose finding aids to more users. Using social media to promote online awareness, while simultaneously improving search engine result rankings for the finding aids, seemed like a potential solution to this problem. With this goal in mind, SHSU researchers selected ten social media sites to test the assumption that posting information about finding aids to social media would be an effective marketing strategy. Following three months of posting information about finding aids while tracking user traffic to finding aids from social media sites, the research findings indicate that a combination of certain social media sites, in this case WordPress, Facebook, and Twitter, provides a better marketing strategy for getting the word out about archival collections. Additionally, the researchers confirm that posting to social media improves search engine result rankings for the finding aids. Overall, the SHSU researchers' results concur with the perception that using social media tools is an effective marketing strategy for an organization desiring to promote online awareness and improve search engine result rankings for finding aids.
\end{abstract}

(c) Felicia Williamson, Scott Vieira, and James Williamson. (cc) BY-NC KEY WORDS

Social media, Finding aids, Archival description, Outreach, Marketing 
Tn 2011, Sam Houston State University (SHSU) Special Collections held many 1 interesting and notable manuscript collections, but with no online presence, no publicly accessible finding aids, and no outreach strategy, the department was a hidden gem. After doing research on the best archival description methods and finding aids platforms, the special collections librarian implemented Describing Archives: A Content Standard ${ }^{1}$ and the descriptive tool Archon ${ }^{2}$ in 2012. By 2013, the Special Collections team had processed and described twenty archival collections and placed full finding aids online using Archon. ${ }^{3}$ Despite these efforts, the department still hoped to become better known in the online research environment. Specifically, Special Collections needed a way to promote finding aids to potential users, and social media seemed like the best and most affordable way to do this. In addition, while Google was indexing the Archon finding aids, this indexing was not producing prominent hits in Google's search results, which is problematic in today's research environment.

In response to these problems, the special collections librarian, digital resources librarian, and electronic resources librarian (henceforth known as the research team) designed a study to explore how well social media functions as a way to increase awareness of special collections, increase traffic to finding aids, and, inadvertently to some extent, improve Google search results. The team's best guess was that social media would help promote the finding aids. But would this expectation hold up? And what other interesting observations might be made regarding questions about the differences in social media platforms for promoting special collections, as well as other possibilities such as improving Google search results? In an attempt to address these questions, the research team's study measured traffic to the finding aids via social media posts. The team did discover that some platforms were more successful than others in promoting the finding aids.

\section{Literature Review}

Presently, social media has permeated all forms of communication and the online world. Likewise, the adoption of social media by libraries, museums, and archival institutions for the most part mirrors mainstream adoption of social media. ${ }^{4}$ Concurrently, the literature regarding social media is profuse. However, a large body of this literature, whether business or library oriented, focuses primarily on the importance and implementation of social media, whereas peerreviewed research studies on social media are relatively scarce. ${ }^{5}$ Understandably then, a research study on the subject of using social media to market archival finding aids hosted on the open source application Archon provides a relatively unique look into what in practice is a mainstream marketing tool for libraries and other archival institutions. 
The operating assumption with social media is that it offers an economical means to communicate, whether between users and other users, or institutions and users. In other words, social media provides a tool for marketing. Susanna R. Campbell, Ismet Anitsal, and M. Meral Anitsal conducted interviews to understand why users value social media. One of the reasons included the value in having "[a]ccess to many people." ${ }^{\prime}$ In particular, social media has provided an important bridge for contact and communication with customers. Campbell et al. wrote, "Just as people use social media sites to keep in touch with their friends, companies can use them to keep in touch with customers." They also

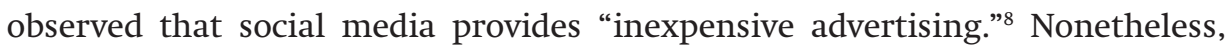
despite this expectation for advertising, users noted annoyance with advertising in social media, which led Campbell's group to admonish businesses for oversaturating social media with advertising. ${ }^{9}$

All this supports what would be considered an economic motivating factor in marketing for libraries and archives. As Sean Heylinger, Juli McLoone, and Nikki Lynn Thomas found, repositories primarily use social media for marketing collections..$^{10}$ Second, the researchers found, social media is used for marketing events. ${ }^{11}$ Yosra Akrimi and Romdhane Khemakhem explained that users find confidence and value within their social media networks that consequently promote a utilitarian value to users (and marketers) through shared content. This motivation for spreading the word, of course, is an important aspect of marketing that multiplies the marketer's audience exponentially, in what can often be personal networks of shared interests. ${ }^{12}$

The library literature contains some case studies and analyses regarding social media and marketing. Shakeel Ahmand Khan and Rubina Bhatti conducted a survey of librarians and LIS school professors to determine perceptions on using social media for library marketing. Despite a small research focus (essentially two universities in Pakistan), the responses indicated a consistently "positive" opinion about the importance of social media for library marketing. ${ }^{13}$ In another study, Lili Luo, Yuan Wang, and Lifeng Han evaluated the effectiveness of a marketing video on students. They concluded that the content must connect to the students' experiences and be presented with a "humorous, light-hearted, and refreshing style." ${ }^{14}$ Their findings pertained to the content of the marketing video and, by extension, may be applicable to content creation on other social media platforms. Selene Colburn and Laura Haines conducted another study on video and social media for marketing in libraries. They analyzed the promotional messages and view counts of YouTube videos about libraries or created by libraries and librarians. The findings highlight important factors in successful videos and are summarized as follows: "Identify strategic promotional goals." "Set measurable goals and make an assessment plan." "Link to the video frequently and in relevant locations." "Showcase the 
library's most unique collections." "Participate in online discussion." "Engage patrons as content creators." "Use humor." "Invest in production values." 15 Dianna E. Sachs, Edward J. Eckel, and Kathleen A. Langan conducted a user survey to determine the value of a library's Facebook page. Results were typical of other writings on social media where Facebook was used primarily for marketing library events and services, but at the same time meant to provide a bridge for communication between the library and users. Other observations included obstacles a Facebook presence might create that are unique to institutions since Facebook was originally intended and is generally used as a personal networking system. ${ }^{16}$

Mira Foster, Hesper Wilson, Nicole Allensworth, and Diane T. Sands studied the marketing value of social media for promoting LibGuides. Before beginning the data collection phase of the study, assessments were made of the LibGuides and their creators along with beginning usage statistics. Following this, they set up Google Analytics to capture usage statistics of the LibGuides during a marketing period when the LibGuides were promoted via blog postings, Facebook, Twitter, and email. While results were generally inconclusive because of the small amount of data collected over brief periods of time, social media contacts like Facebook or email to specific users of shared interest appear to have a higher success rate. ${ }^{17}$

Adam Crymble analyzed the links and content posted by archivists and archival organizations on Facebook and Twitter. He concluded that Facebook and Twitter provide different strengths and weaknesses as communication tools and suggested the importance of using the different social media platforms with strategically different approaches. Areas for consideration included audience type, longevity, and time investment for producing posts. ${ }^{18}$ Melanie Griffin and Tomaro I. Taylor analyzed the social media sites of 125 Association of Research Libraries special collections repositories to assess the return on investment (ROI) social media offers these collections. They concluded that

ARL special collections achieve moderate success when using social media to publicize institutional holdings, events, and activities. Success, determined by number of departmental posts and the resulting likes, shares, and comments from external users, can be realized as potential gains . . . to staff investment, whereby special collections use of social media indicates demonstrable increases in visibility within and external to the parent organization. ${ }^{19}$

\section{Methodology}

With the aforementioned goals of increasing awareness and search result rankings for finding aids using social media, the research team selected ten 
social media sites to disseminate information about SHSU archival collections. Seven social media sites were chosen using Alexa rankings. ${ }^{20}$ The research team also included three social media sites that were not listed in the top twenty at the time (WordPress, Pinterest, and Historypin), because they had been touted in the literature as a way of attracting interest to collections. ${ }^{21}$ The complete list of social media sites used during the research phase is

- WordPress

- Tumblr

- Facebook

- Google+

- Myspace

- Flickr

- LinkedIn

- Pinterest

- Historypin

- Twitter

Before the project could begin in earnest, the team worked to understand the nature of each site and how best to use its unique features. Each community has its own characteristics and set of rules, and each site's users are interested in different things.

After selecting the sites, the research team spent six months attracting followers and promoting general archival content on each site. The research team avoided posting finding aids during this phase for two reasons. First, the team wanted to avoid potential duplication or contamination by earlier posts, and, second, the team wanted to reserve the finding aids and the content they represent for the research phase. During this time, the research team posted about a wide range of materials from SHSU collections, often choosing visually interesting materials. When posting, the team changed the tone from academic to humorous when the content or the nature of the social media site dictated. The team also followed fellow institutions or users who showed an interest in archival topics or in subject matter represented in SHSU's collection. By so doing, the team was able to draw attention to SHSU sites as well as see what worked well for other institutions. This approach was instrumental in building followers.

To monitor the traffic from the social media sites to the Archon finding aids, the research team chose Google Analytics, which tracked many of the necessary data elements using its "campaign" feature. The research team added tracking code provided by Google Analytics to the Archon footer template, which reproduced the tracking code on each page of the Archon website. The team then added customized values into the parameters available for a Google Analytics campaign into the finding aid URL, which was later embedded within 
the social media post. The code contained information about the campaign (ex. utm_campaign=archon), the type of traffic (ex. utm_medium=referral), and the source (ex. utm_source=tumblr). From this the team was able to collect information on where visitors were coming from, what they viewed, and how long they stayed on each site. When referring to posts on social media sites and the data collected from the Google Analytics embedded coding, this article uses the term "tracking URL."

After building an audience and learning the various eccentricities of each social media community, the research team crafted posts using information from the biographical/historical and scope and content notes of each selected finding aid. In addition, images from each collection accompanied these descriptions. Finally, the tracking URL was included, usually at the bottom of the post. The team used the full URL instead of a shortened version because not all sites have the same permissions for displaying links. Because of the nature of each social media site, the posts had to be modified from site to site. No matter the modification, each post always contained some biographical and historical information and the tracking URL.

Once posts with the appropriate description and tracking URL were created, the team began the twelve-week research phase, which lasted from October 2013 to December 2013. Every Tuesday morning between 10:00 a.m. and 10:30 a.m., a post was released on each site featuring the selected finding aid for that week. The research team chose this time because Tuesday is positive for workplace productivity, it avoids some of the glut of social media postings, and it worked with other workplace duties and workflows of the primary poster (the digital resources librarian).

The finding aid for each week was chosen based on its topic and its possible appeal within the social media community. The research team planned a release schedule for the finding aids, spreading out collections that featured similar topical content throughout the research phase.

In addition, the research team crafted an email to submit to selected listservs, asking listserv participants to visit the Archon site. The email contained a tracking URL like the social media posts. The research team selected two listservs, the Archives and Archivists List and Arkansas History List. ${ }^{22}$ The team chose these two listservs because of their reputation for activity among their members and because the team was able to obtain the number of subscribers for each listserv (631 and 306 respectively). The email contained information about SHSU's Archon page, how SHSU Special Collections was using Archon to link collections to item-level descriptions in CONTENTdm, and, finally, the tracking URL. ${ }^{23}$ This broad email was sent to each listserv on October 9, 2013, and was distributed only once to avoid any appearance of spamming. 
To catch anyone who may have missed the tracking URLs posted on the listservs or embedded on the social media posts, the team posted a survey on the Archon site asking how visitors had found the Archon site, what kind of users they were, and if they had specific research interests. The team used the survey software SurveyMonkey to host and conduct the survey. This survey appeared as a pop-up on the homepage of the Archon site. With only fifteen responses almost entirely coming from the listserv emails, the results of this survey did not add significantly to the study's findings.

\section{WordPress}

The research team started by establishing a WordPress blog. The team chose WordPress because of its popularity in the blogging community and because of its social media flexibility (it allows the poster to share content on other social media platforms). WordPress is set up as a website and publishing platform. It uses a rich text editor to publish content and allows flexibility in the design of the blog by adding widgets and in the ability to change CSS code. Users of the free online platform (which the team used) have a news feed, the ability to follow blogs, and the ability to search tagged articles.

With WordPress, tags play a key role in discoverability. Not only are tags a way for users to find a post, they play a part in the indexing of posts in search engines. Significantly, test searches for finding aids found WordPress posts based on the terms that had been tagged. Tags are one way to reach those outside the WordPress community and gain followers.

One of the key differences between WordPress and other social media sites is that a visitor does not have to be a member of WordPress to follow the posts. WordPress allowed the team to place a widget allowing users to subscribe via email instead of going through the site as a member. Visitors also have the ability to share posts through a number of social media outlets (such as Facebook, Twitter, etc.) using buttons embedded in each post. These features allowed the team to reach a wider audience.

As for the content itself, the research team experimented with various lengths of posts: some went into great detail and contained numerous images, while others were short and only contained one image. The team also created humorous GIFs from collection materials. GIF (Graphics Interchange Format) is a bitmap image format that supports animations and is widely used throughout the Web. In the team's experience, in-depth posts received greater attention, especially when properly tagged. Short, flashy posts with GIFs did well within the WordPress community, but lacked a broader audience. For an example of a blog post with text from the finding aid's biographical/historical note and scope 


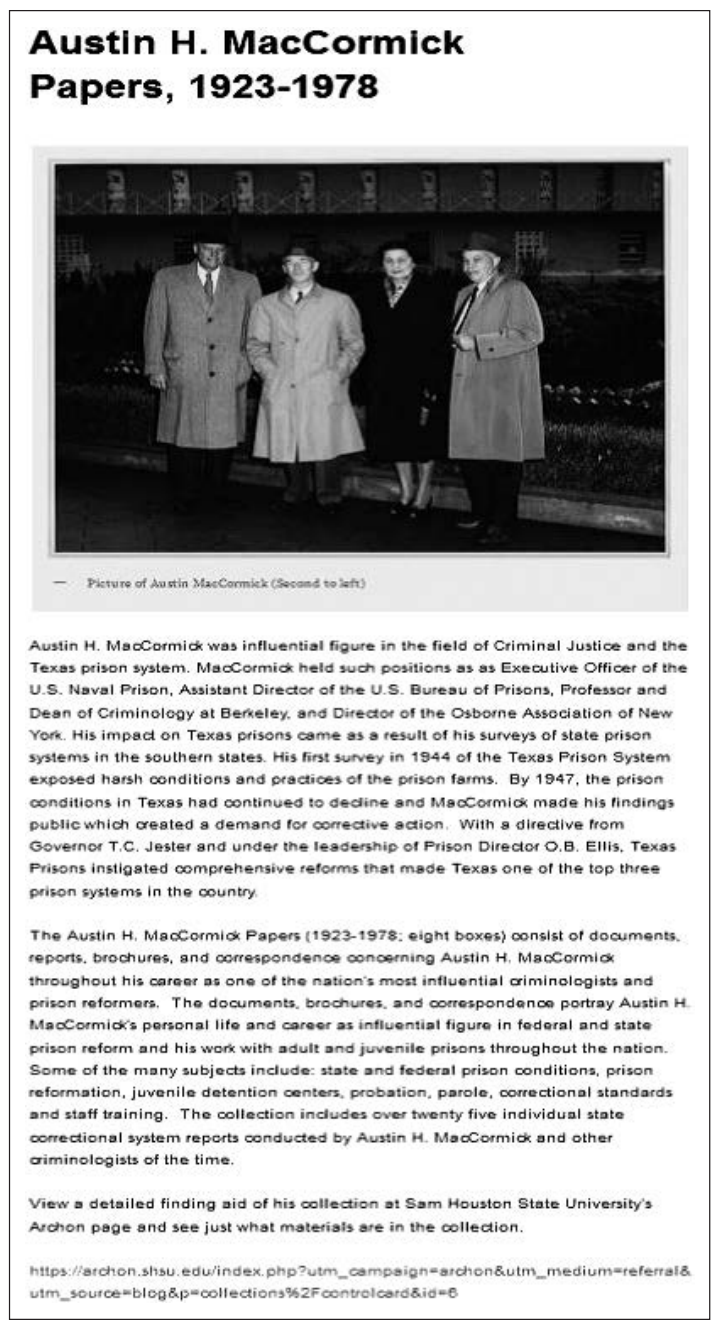

FIGURE 1. This WordPress blog post contains text from the finding aid's biographical/historical note and scope and contents note in addition to a visual from the collection and the tracking URL.

and contents note in addition to a visual from the collection and the tracking URL, please see Figure 1.

\section{Tumblr}

Tumblr is a micro-blogging platform with a stronger and more connected community atmosphere than WordPress. Users publish and post material as if it were a blogging platform, but the interface (or dashboard) for members of the Tumblr community relies heavily on the newsfeed style. The Tumblr blogs that 
a person follows are presented as a scrolling list of posts. This means anyone posting on Tumblr must stand out among all the other content providers a user may be following. This may be a challenge for institutions that may not have the time and staff to post large amounts of content throughout the day so that the Tumblr audience will notice. Timing, organization, and a niche play heavily in creating a successful Tumblr following.

Upon joining Tumblr, the research team sought out related organizations and began cultivating relationships with other Tumblr entities by "favoriting" and sharing their materials. The team also reached out to colleagues in the library and archival fields who maintain personal Tumblr accounts. These librarians and archivists, affectionately called "Tumblrarians," have taken their descriptive and organizational skills to Tumblr and act as curators of content, even creating controlled vocabularies for library and archives content on Tumblr. Tumblrarians maintain an active community of users who share articles, research materials, and anything library related. ${ }^{24}$ Using their controlled vocabularies is a smart way to begin a relationship with them.

For a community like Tumblr, fun, entertaining, or eccentric content is often best. As mentioned earlier, posts from Tumblr will appear in a follower's newsfeed. Most followers see content streams from hundreds of Tumblr accounts, so quirky material may help an institution stand out in a crowded newsfeed. Items such as miniature or uniquely made books received attention from the Tumblr community. ${ }^{25}$ Posts with GIFs also helped increase activity among followers and bring in new audiences. ${ }^{26}$ Among the Tumblr community, GIFs are ubiquitous, drawing from movies, television, and so on. They are often humorous or drive home a point that a poster is trying to make. Using Photoshop, the team created short animation GIFs of SHSU's miniature and uniquely made books, as well as humorously animated GIFs from a large art collection in the archives. These GIFs were well received, and several were selected to be featured on Tumblr Radar (a showcase of posts selected by Tumblr that appears on each user's dashboard).

When the team began the research phase, these experiences were incorporated into a strategy for posting finding aids. The team included the same images and long-form description from WordPress and tagged them with locally controlled vocabulary as well as vocabulary curated by the Tumblrarians. When possible, the team converted images into animated GIFs to try to attract more attention.

\section{Facebook}

The library at SHSU already maintained an active Facebook account, and the research team opted to post content to this feed. While this account already 
had an audience, SHSU Special Collections had not posted there before. To increase campus awareness of SHSU Special Collections in preparation for the research phase, the team posted about archival stories, events, and materials (with modified or shortened posts taken from Tumblr and WordPress) every Tuesday and Thursday, trying to signal to users that Tuesdays and Thursdays were about archives even before the research phase began.

Unlike WordPress or Tumblr, Facebook is not conducive to lengthy, historical descriptions of collections. In fact, because most users view items in their newsfeeds and newsfeed versions are truncated with "read more," which eliminates quite a bit of the post, these posts were necessarily shorter. Using the descriptions constructed from the biographical/historical and scope and content notes, the team shortened the posts to enough basic information to tell a user what a collection was about and what types of materials it contained. Often, the team simply posted the image in Facebook's photo album and included the shortened description with the tracking URL. See Figure 2 for an example post.

\section{Google+ and Myspace}

The research team created an account for both Google+ and Myspace and posted content that mirrored the Facebook posts. Myspace, a once popular site, continues to decline despite its purchase by a group including Justin Timberlake. ${ }^{27}$ The research team tried locating other archival or historical institutions on Myspace but had little luck. To appeal to Myspace's musical community, the team crafted music playlists, so if someone found the site, it would seem active and interesting. Fellow archival institutions could be found on Google+, so the team added them to SHSU Special Collections' circle of Google+ friends.

As they had done on Tumblr and WordPress, the team posted about events, archival materials, images, and so forth on Google+ and Myspace to build audiences before the research phase began. While the number of followers for each of these platforms was not significant, Google+ did help postings get indexed by Google. When it came to the research phase, the team used the same strategy as it did with Facebook by posting images with truncated descriptions, hoping to avoid dreaded "read more" abbreviated posts.

\section{Flickr}

Flickr has historically been used to promote archival collections and is a popular tool used to crowdsource image tagging. A number of topic- or genre-specific groups exist within Flickr that can be used to post archival 


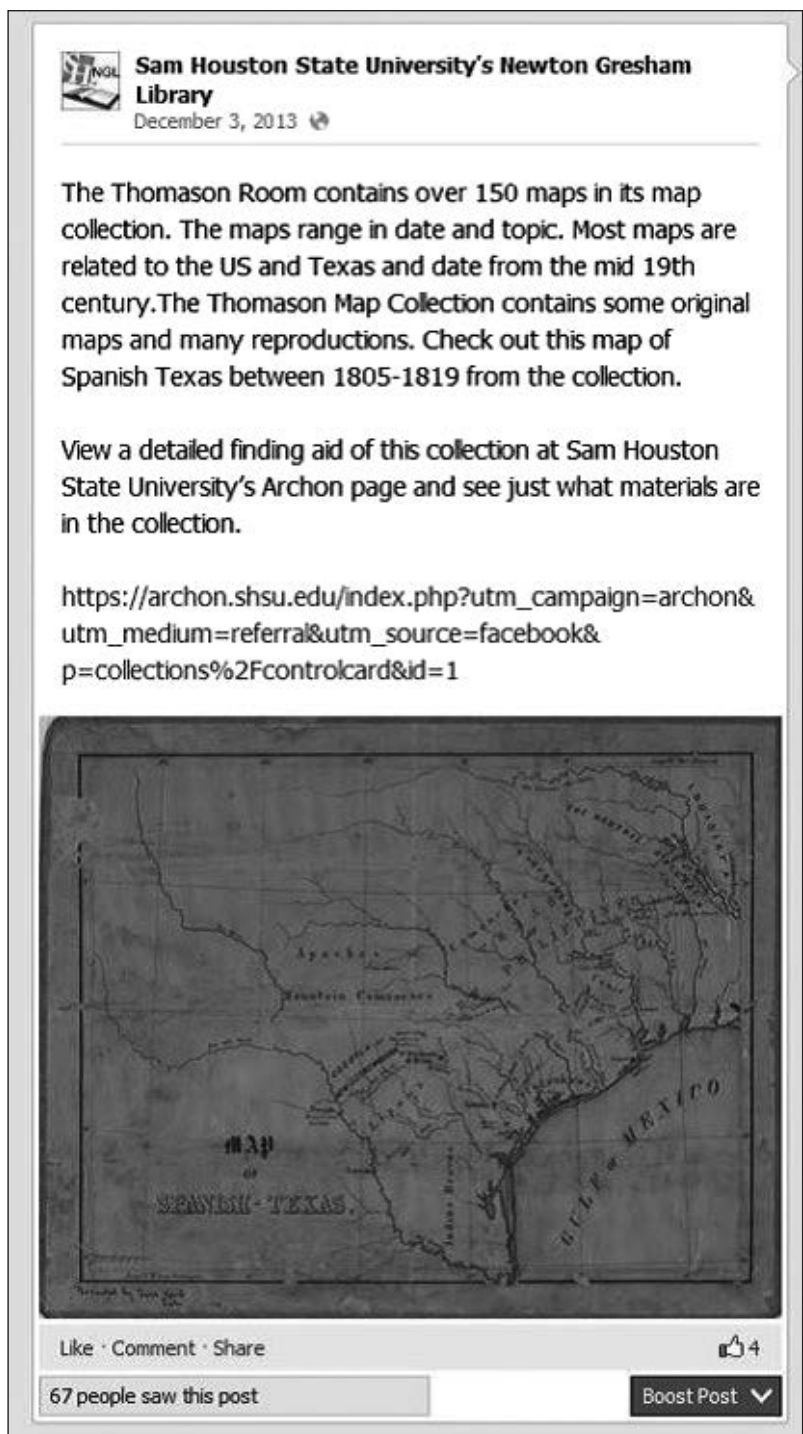

FIGURE 2. This typical Facebook post contains text and an image.

images and enhance marketing success. The research team joined two groups (ArchivesOnFlickr and Archives and Archivists on Flickr) because of their recent activity and their rights restrictions, which enabled the team to post images with copyright restrictions. The team posted to those groups leading up to the research phase. When the research phase began, the team posted preselected images along with a full description of the collection. Because of how photos in Flickr are first viewed in a photo stream with only images and titles, the full length of the description is always a link away. The team simply uploaded 
images to the SHSU Flickr account in addition to the group accounts and added descriptive tags.

\section{LinkedIn}

Like Flickr, LinkedIn maintains a number of active archival groups that the research team joined, including the "historians, librarians, and archivists" group, as well as a group associated with SHSU. The team also created its own group. The research team determined that LinkedIn has a more formal community atmosphere and decided to post once in each group, though the team did post weekly content to the project-specific LinkedIn group. LinkedIn focuses on information rather than visual elements, so the team had difficulty adding images, and the descriptions had to be shortened to meet a character limit. The team also had difficulty attracting users to its group. LinkedIn is closely tied to the business community, and the group-specific page had very little business focus. LinkedIn can be a venue for sharing archival topics, but the groups with more activity, such as the "historians, librarians, and archivists" LinkedIn group, have a professional focus.

\section{Pinterest}

Pinterest has become one of the hot new social media sites in the last few years with users pinning photos of crafts, recipes, and more on their boards for followers to share. Increasingly, users from historical and archival institutions have become involved by posting largely visual content. Following the steps established on the other sites, the team located images, created several topical boards, and followed other institutions. The team was able to streamline the workflow by using embedded features in Tumblr, Facebook, and Flickr to pin items to the SHSU board. Pinterest does have a limit of 500 characters, so brevity is key. Descriptions need to be short and contain key subject terms for users to locate the pins. Pinterest differs from most of the social media sites in that it does not provide the ability to tag posts or a clear method for posting pins so that they appear on the main (highly visible) subject boards. The approach to Pinterest during the research phase did not change; the team uploaded the images along with a description and tracking URL.

\section{Historypin}

Historypin focuses on creating collections or virtual tours by pinning images to a geographical location. On Historypin, users can follow other 
archival institutions, but much of the focus is on a channel or page. The research team built up content on the SHSU channel, creating a handful of collections and pinning materials to maps. When it came time to post finding aids, it was possible to place the full description and link along with relevant subject terms and dates. However, not all the images selected had a geographical element, which made pinning the item to a map difficult. When it came to placing the items on a map without a geographical element, the team pinned these items to the library's location. Historypin generated views to materials before the research phase but lacked the communal aspect that benefits other social media sites.

\section{Twitter}

Although the SHSU Library maintains an active Twitter account, it is used for general library publicity and announcements. The research team decided to establish an archives-specific Twitter account and posted to both during the research phase. To increase the presence of this new account, the team followed Twitter accounts associated with libraries and archives, and personal accounts associated with librarians and archivists in the hope that they would in return follow the SHSU Archives account. This method resulted in increased Twitter followers. During the building phase, the team highlighted materials from the general archival collections, posted links to output on Tumblr and WordPress, and shared posts from other institutions.

Much like Tumblr and Facebook, Twitter shows tweets in a newsfeed format, and, because of a constant stream of content, the team determined that it would be impossible to catch users' attention with one finding aid post per week. Therefore, the team continued posting about other materials in the collections in addition to the weekly finding aid posts during the research phase. Instead of a flood of visuals, Twitter is a flood of text, and visuals are helpful. Of course, Twitter is well known for its 140-character limit. Adding an image and a link to the tweet severely decreases the available number of characters. See Figure 3 for an example tweet.

SHSU Archives@SHSUArchives.Nov 5

View the manuscript collection of famed Texas prison reformer and Dean of Criminology at Berkley, Austin MacCommick. archon.shsu.edu/index.php?utm_

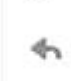

FIGURE 3. This typical tweet invites users to view a finding aid at the Archon site. 


\section{Findings}

After establishing a presence on ten social media platforms and building followers for six months, the team began the research phase in October 2013. Using Google Analytics, the team examined which methods of social media outreach would yield the most "click-throughs." A click-through is when a user accesses a finding aid by clicking on a tracking URL.

The main advantage for implementing a Web-based finding aid program like Archon or ArchivesSpace is the potential for increased Web visibility. Certainly one of the main reasons the team at SHSU implemented Archon was the potential to improve Google search results. Before the research project, SHSU's finding aids were already indexed by Google and appeared in Google search results. However, the ranking of SHSU finding aids on Google often left the finding aid on the second page of results or lower. Additionally, the research team desired further modes of visibility beyond Google rankings, including increased awareness of SHSU Special Collections materials within the national research community.

Google Analytics collects information about traffic to finding aids from various sources, including traditional search engines (Google, Bing, Yahoo, etc.); referrals, which include all traffic from outside websites that contain links to finding aids such as the library website; the digital collections websites; LibGuides and the like; the listserv posts with tracking URLs; and, finally, traffic from designated social media sites also with tracking URLs. Figure 4 shows the basic breakdown of website traffic.

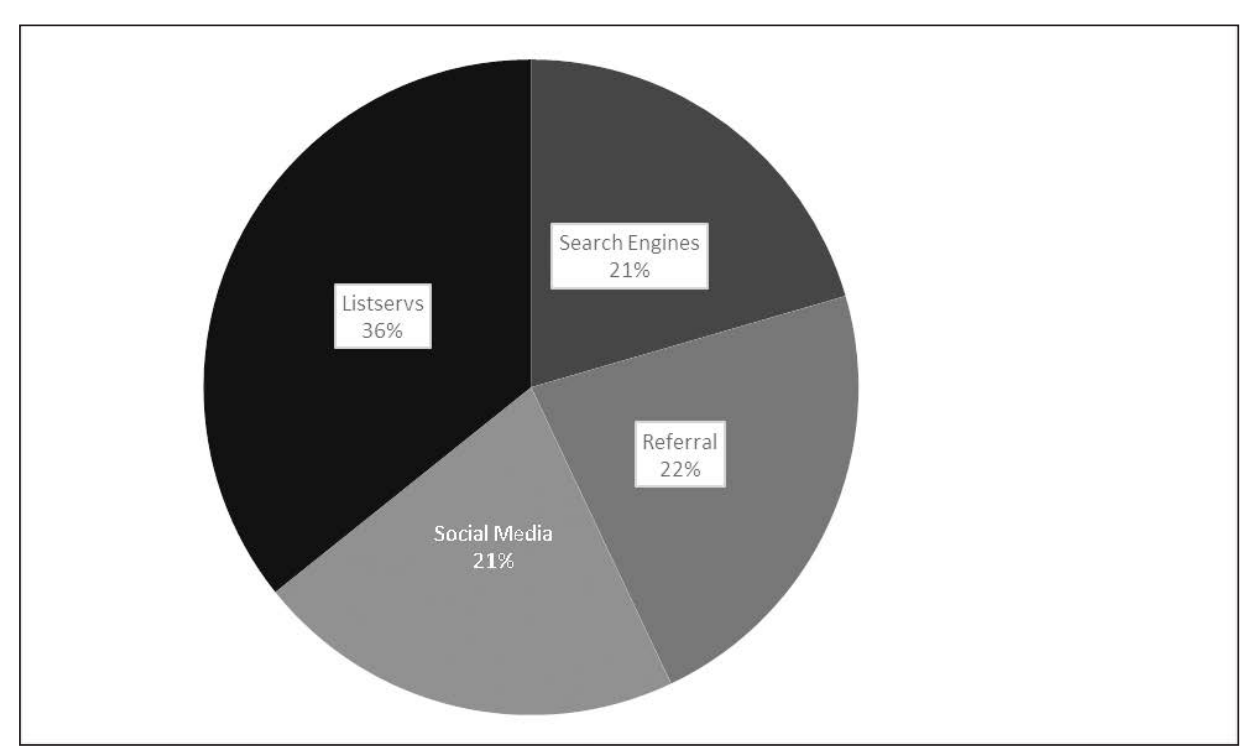

FIGURE 4. Web traffic generating to the Archon Finding Aids site is broken down in this pie chart. 
There were a total of 512 visits to the Archon Finding Aids site during the research phase. As Figure 4 illustrates, the click-throughs to finding aids produced by search engines equaled traffic from social media platforms. In addition, by posting once to two listservs (Archives and Archivists with 631 subscribers at the time of the post and Arkansas History with 306 subscribers), the finding aids received a large one-time burst of activity with 183 click-throughs. Referral traffic (from other static websites like the library website, LibGuides, the digital resources website, etc.) resulted in 115 click-throughs. The referral traffic provided a constant source of click-throughs and seems sustainable. Social media traffic, traffic produced by clicking through a social media post via a tracking URL, resulted in 109 click-throughs.

The research reveals three social media platforms that stand above the rest in facilitating archival research: WordPress, Facebook, and Twitter. See Figure 5 for a full breakdown of click-throughs by social media platform. With thirty click-throughs and a large number of interactions with users, WordPress was the most successful social media platform for marketing archival research materials in an online environment. WordPress allows for a detailed write-up on each finding aid pulled from both the biographical/historical and scope and contents notes along with flexible options for presenting visual content. A WordPress entry is also easy to find and has an intuitive interface for many users. Facebook is, for now, the most popular social media site in the world. ${ }^{28}$ Facebook allows for a brief introduction to the finding aid with an image. The research team used the SHSU Library Facebook page with an established local audience-these users are loyal and interested in local research topics. With twenty-five click-throughs, Facebook was a close second to WordPress. Finally, Twitter surprised the research team. Despite the limited 140-character

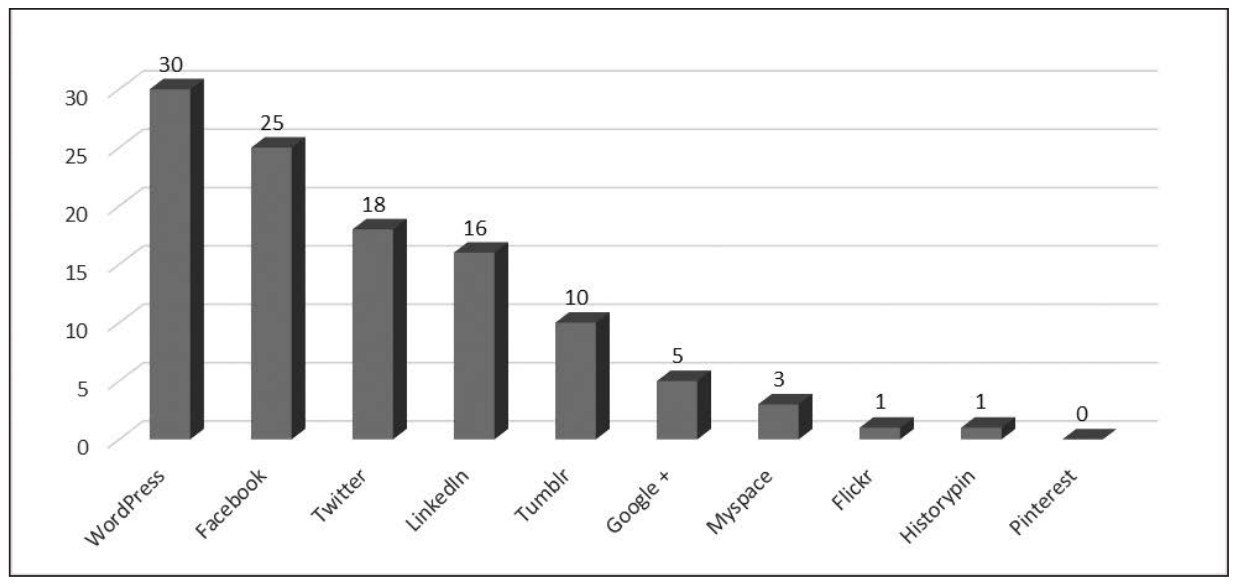

FIGURE 5. This graph shows a breakdown of click-throughs by social media site. 
version of the biographical/historical note with the tracking URL, the team was impressed that eighteen people clicked through to a finding aid from Twitter.

Next, LinkedIn with sixteen click-throughs, Tumblr with ten, and Google+ with five click-throughs were less successful but yielded a revealing set of results nonetheless. In particular, the sixteen click-throughs from LinkedIn occurred on the same day as a result of a post sent to specific groups of archives and history enthusiasts. Because the LinkedIn community is more defined-assuming membership in archives or history-specific LinkedIn groups-going to these groups again and again may not be sustainable. Tumblr, with ten click-throughs and a great deal of interaction with users, was a surprise. Though the number of click-throughs was a third of that of WordPress, Tumblr is popular and effective as a general purpose marketing and outreach tool. The research team also anticipates that, as the Tumblr community grows, the number of people who click through will increase. Google+ garnered almost no interest from researchers but did generate five click-throughs. However, Google+ is an important factor in increasing one's rank in Google indexing. ${ }^{29}$

Finally, Myspace with three click-throughs, Flickr and Historypin with one each, and Pinterest with zero round out the list of social media platforms. The research suggests that current users are not active on Myspace in a way that is useful for promoting finding aids. Flickr has the wonderful capability of displaying high-resolution images but does not display text or links without clicking into the post. This may partially explain the failure of Flickr to produce clickthroughs. The population of users on Historypin is not interacting with posts so far. Similarly, Pinterest users did not respond to pinned finding aids. For both Historypin and Pinterest, the interface and core community interests may be contributing factors. Further, the small image with a limited description and a nearly invisible or cut-off tracking URL might not encourage click-throughs. Pinterest users are often surfing Pinterest for recipes or craft ideas (although a community of people who pin historical images by theme or era is growing). ${ }^{30}$

\section{SOCiAl Media Followers}

Figure 6 shows the number of social media followers compared to clickthroughs generated by each platform. The chart shows that, although some sites had a higher number of followers, this did not always result in more clickthroughs. The team is interested in further research into sites with higher numbers of users and how running a similar experiment with a larger audience might change the number of click-throughs. ${ }^{31}$

At the outset of the research project, certain finding aids-for example, Wild

Dog (a Beat Generation poetry collection), or the SHSU Map Collection-seemed 


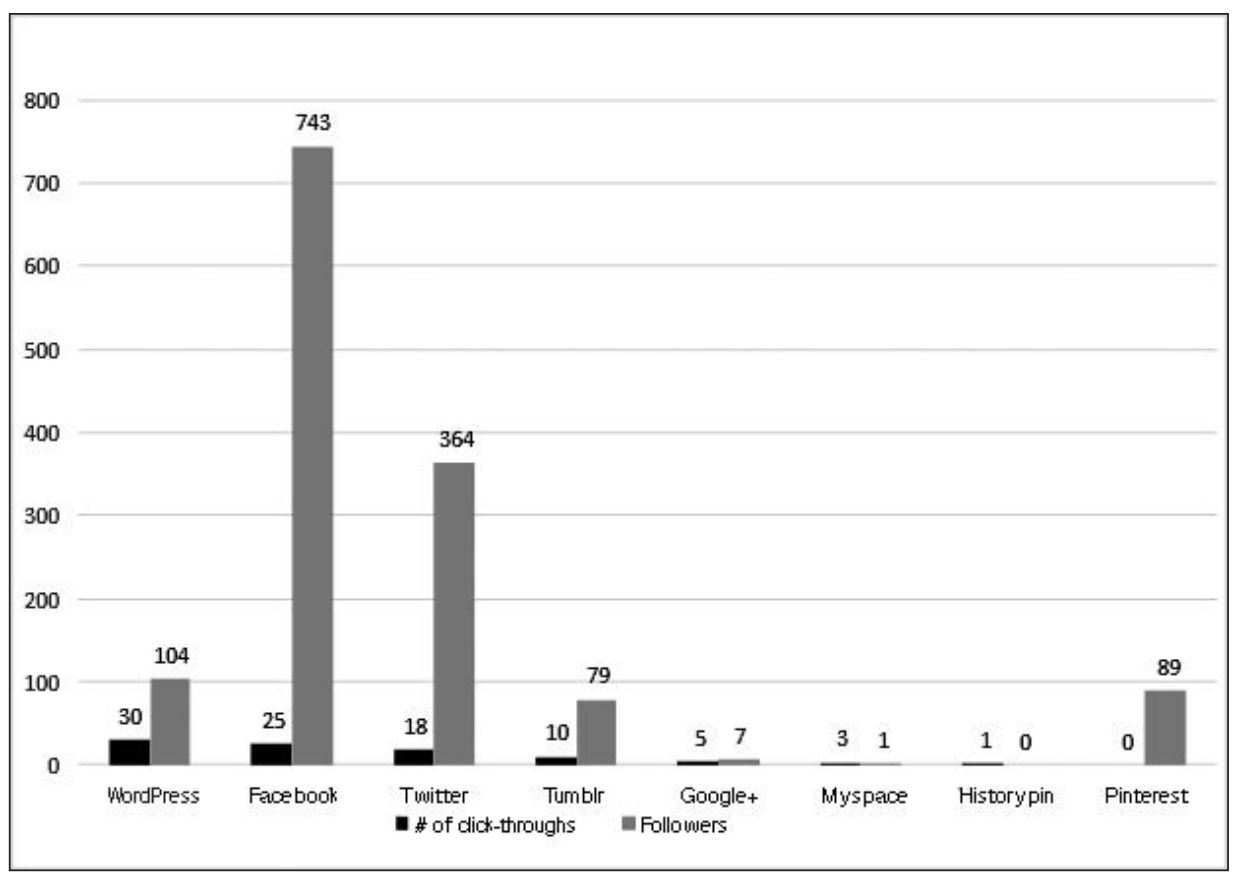

FIGURE 6. This chart compares the number of social media followers to click-throughs generated by each platform.

to be probable online success stories, because they comprise highly visual, engaging content. The SHSU Map Collection did in fact garner the most clickthroughs with fourteen (posted on December 3, 2013). The SHSU Map Collection posts contain vivid, detailed visual content and cover popular research topics such as railroads and Texas history. The SHSU Map Collection posts also generated the most user activity by far, with forty-two likes and reblogs. The Wild Dog collection generated four click-throughs and the second highest number of likes and reblogs with thirteen (see Table 1 for a breakdown of user activity by collection).

Table 1. User Activity by Collection

\begin{tabular}{|l|l|l|}
\hline \multicolumn{1}{|c|}{ Finding Aid } & \multicolumn{1}{c|}{ Activity } & \multicolumn{1}{c|}{ Date Posted } \\
\hline Map Collection & 42 likes/reblogs/etc. & December 3, 2013 \\
\hline Wild Dog Magazine Collection & 13 likes/reblogs/etc. & October 29, 2013 \\
\hline World War I Artifact Collection & 12 likes/reblogs/etc. & December 17, 2013 \\
\hline $\begin{array}{l}\text { Sanford Bates Collection (Crimi- } \\
\text { nal Justice) }\end{array}$ & 6 likes/reblogs/etc. & October 15, 2013 \\
\hline $\begin{array}{l}\text { John Warren Smith Papers } \\
\text { (Research Collection) }\end{array}$ & 5 likes/reblogs/etc. & November 26, 2013 \\
\hline 3 others tied & 4 likes/reblogs/etc. & \\
\hline
\end{tabular}


While criminal justice is SHSU Special Collections' foremost collection development area due to SHSU's premier College of Criminal Justice, the research team was unsure how many click-throughs criminal justice collections would generate. However, three criminal justice collections-Austin MacCormick (with ten click-throughs, posted November 5, 2013), James V. Bennett (with nine clickthroughs, posted October 8, 2013), and Ruiz vs. Estelle (with eight click-throughs, posted November 12, 2013)-were in the second-highest category of click-through success. Post date did not seem to affect success rate.

Finally, the local history collection, the John Warren Smith Papers (with eight click-throughs, posted November 26, 2013) and the Sanford Bates Collection, another criminal justice collection (with seven click-throughs, posted October $15,2013)$ round out the list of click-through success stories. The apparent popularity of the John Warren Smith Papers seems to be an anomaly best explained by local history researchers who might be interested in its contents, which are rich in Huntsville and Walker County history. Researchers clicking through to finding aids from IP addresses in Walker County, Texas, generated more views than any other point of origin. The research team's IP addresses were eliminated from Google Analytics' tracking. Table 2 shows the breakdown of clickthroughs by collection.

Table 2. Click-throughs by Collection

\begin{tabular}{|l|c|l|}
\hline \multicolumn{1}{|c|}{ Finding Aid } & Click-throughs & \multicolumn{1}{|c|}{ Date Posted } \\
\hline Map Collection & 14 & December 3, 2013 \\
\hline Austin MacCormick (Criminal Justice) & 10 & November 5, 2013 \\
\hline $\begin{array}{l}\text { James V. Bennett Collection (Criminal } \\
\text { Justice) }\end{array}$ & 9 & October 8, 2013 \\
\hline $\begin{array}{l}\text { Ruiz vs. Estelle Collection (Criminal } \\
\text { Justice) }\end{array}$ & 8 & November 12, 2013 \\
\hline $\begin{array}{l}\text { John Warren Smith Papers (Research } \\
\text { Collection) }\end{array}$ & 8 & November 26, 2013 \\
\hline Sanford Bates Collection (Criminal Justice) & 7 & October 15, 2013 \\
\hline
\end{tabular}

While click-throughs are the barometer of success for marketing finding aids, many social media posts were viewed without resulting in click-throughs to finding aids. See Figure 7 for an analysis of one popular collection's views versus click-throughs on Facebook, Flickr, Google+, and Historypin.

\section{USER BEHAVIOR}

Users reacted to posts in some predictable and some less than predictable ways. Users were most active on the first day the finding aids were posted on 


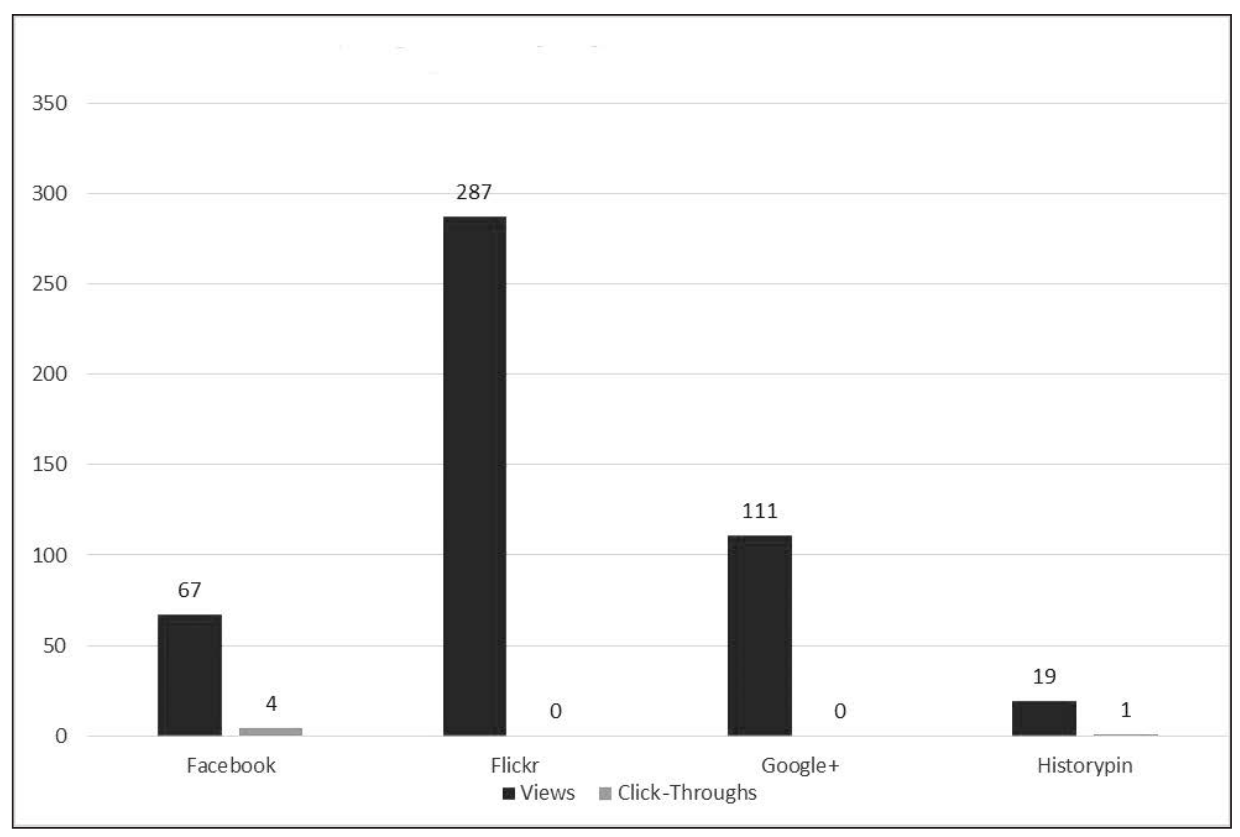

FIGURE 7. This analysis of views of and click-throughs to the SHSU Map Collection shows Flickr the clear leader.

the social media sites (Tuesday). There were on average forty click-throughs on Tuesdays, seventeen click-throughs on Wednesdays, twenty-two click-throughs on Thursdays, ten click-throughs on Fridays, two click-throughs on Saturdays, ten click-throughs on Sundays, and eight click-throughs on Mondays (see Table 3).

Table 3. Click-throughs vs. Day of the Week

\begin{tabular}{|l|c|}
\hline \multicolumn{1}{|c|}{ Day of the week } & Click-throughs \\
\hline Tuesday & 40 \\
\hline Wednesday & 17 \\
\hline Thursday & 22 \\
\hline Friday & 10 \\
\hline Saturday & 2 \\
\hline Sunday & 10 \\
\hline Monday & 8 \\
\hline
\end{tabular}

Significantly, the average duration of users on the social media platforms indicated they were looking at research material, not jumping into the site and jumping right out. The average duration of a user on Twitter was 00:02:28 (eighteen click-throughs/users total). The average duration of a user on LinkedIn 
was 00:02:06 (sixteen click-throughs/users total). The average duration of a user on Facebook was 00:02:05 (twenty-five click-throughs/users total). The average duration of a user on WordPress was 00:01:33 (thirty click-throughs/users total). The average duration of a user on Tumblr was 00:01:25 (ten click-throughs/users total). Other sites had an average duration of a few seconds (see Table 4).

Table 4. Click-through Duration

\begin{tabular}{|l|c|c|}
\hline \multicolumn{1}{|c|}{ Social Media Site } & Click-throughs & Duration \\
\hline Historypin & 1 & $00: 08: 46$ \\
\hline Twitter & 18 & $00: 02: 28$ \\
\hline Linkedln & 16 & $00: 02: 06$ \\
\hline Facebook & 25 & $00: 02: 05$ \\
\hline WordPress Blog & 30 & $00: 01: 33$ \\
\hline Tumblr & 10 & $00: 01: 25$ \\
\hline
\end{tabular}

Interestingly, most users were viewing these finding aids on personal computers. In fact, only 9 out of 109 click-throughs were generated from mobile devices. This was one of the surprising results from this study. The research team anticipated many users would use apps (specifically the Twitter or Tumblr app) on their mobile devices to access these finding aids. WordPress generated twenty click-throughs from a Microsoft Windows PC, five click-throughs from a Macintosh PC, and three click-throughs from an Apple iOS (mobile device). Twitter generated sixteen click-throughs from a Microsoft Windows PC and two click-throughs from a Macintosh PC. Facebook generated fourteen clickthroughs from a Linux PC, ten click-throughs from a Microsoft Windows PC, and one click-through from an Apple iOS mobile device.

\section{Practical Applications}

This study considered a successful user interaction to be someone viewing a post on a social media platform hosted by SHSU Special Collections and clicking through to the finding aid, with the end goal that, if that finding aid was pertinent to their research, they would visit SHSU Special Collections to conduct archival research. An additional goal was to increase visibility and accessibility to archival collections at SHSU. While many archival repositories are known to a specific audience (local community, campus community, or international researching community), many repositories wish to expand their reach to new potential researchers. This was certainly the case at SHSU, and the research team believes many other institutions are in a similar push to enhance their 
impact and reach. In addition, in a research environment where many users, even high-level researchers including $\mathrm{PhD}$ students and faculty members, expect to be able to start and, in some instances, complete their surveys of resources online, placing archival collections or at least finding aids to those collections in a Google-search environment is an important and, some would argue, imperative step forward. For today's researchers, page rankings matter, so getting Archon finding aids bumped up to the first page and increasing the number of access points on that first page are significant results. ${ }^{32}$

Indeed, the researchers saw that posting finding aids on social media does increase the ranking of those finding aids on Google. Not only is the finding aid itself higher in the search results, but the additional social media posts create multiple points of entry for each finding aid. For instance, before the research project, the Sanford Bates finding aid was indexed on the second page of Google search results. Now, the finding aid is on the first page of search results alongside two additional points of entry for potential scholars to find the

\section{Sanford Bates Collection, 1906-1972 | Thomason Special ... https://archon. shsu.edu/?p=collections/controlcard\&id=2 - \\ The Sanford Bates Papers (1906-1972; fifty two boxes) documents the life of one of the country's most influential criminologists and prison administrators. \\ Prisons and Beyond. By Sanford Bates. (New York: The ... ajp.psychiatryonline.org/article.aspx?... - American Journal of Psychiatry v by M Sukov - 1937 \\ Prisons and Beyond. By Sanford Bates. (New York: The Macmillan Company, 1936.) \\ Reviewed by Marvin Sukov. Am J Psychiatry 1937;94:235-236. View Author ..}

\section{Sanford Bates - AlcatrazHistory.com}

www.alcatrazhistory.com/rs2.htm -

Working together with Federal Prisons Director Sanford Bates, the new Warden devised new guiding principles under which the prison would operate. To begin ...

\section{Sanford Bates | Out of the Box!}

https://nglarchivesandspecialcollections.wordpress.com/tag/sanford-bates/ -

Oct 15, 2013 - Sanford Bates had a storied career in the field of law and criminal justice. He was practicing lawyer in Boston, member of the Massachusetts ...

\section{Federal Bureau of Prisons | Out of the Box!}

nglarchivesandspecialcollections.wordpress.com/.../federal-bureau-of-pri... . Nov 5, 2013 - SHSU_Bates. Sanford Bates (on left) outside the Bureau of Prisons. Sanford Bates had a storied career in the field of law and criminal justice.

FIGURE 8. SHSU maintains links for three of the top five results on the first page of a Google search for Sanford Bates. 
Bates Collection at SHSU. Indeed, as seen in Figure 8, SHSU maintains links for three of the top five results on the first page, including two WordPress entries. Specifically, this list was generated by typing in Sanford Bates, a relatively unique name. For collection titles with less unique names, the results lists are less packed with SHSU finding aids and social media posts. For instance, a search for Wild Dog Collection resulted in two out of the top ten results (including the Archon finding aid link and, perhaps significantly, a Google+ post from SHSU), but the first page also lists many other non-SHSU links posts about wild dogs and the like.

\section{Recommendations}

Though posting to the listservs produced the highest ROI (with 183 clickthroughs to the finding aids generated from a one-time post), listservs and LinkedIn are great resources for announcing collections or events but do not provide an ongoing marketing tool for finding aids.

Posts about finding aids on sites like Flickr, Pinterest, and Historypin were viewed at a steady rate (probably due to interactive ease and visual content) but did not result in a significant number of click-throughs. Thus, though they have a place in an overall marketing strategy, the ROI for marketing finding aids is not high.

Similarly, Tumblr, Facebook, and Twitter were viewed and received a medium-high number of click-throughs. Tumblr attracted the fewest click-throughs among these, but it was the most interactive interface for user involvement with the archival collections online. Because of this, the team believes that Tumblr will continue to grow as a valuable online community for marketing finding aids. Conversely, Historypin and Myspace were not successful for marketing finding aids. Facebook and Twitter were reliable sources of both views and clickthroughs and worked well together for posting and marketing finding aids. Finally, with the most click-throughs per follower and the most interactions with followers, WordPress provides an impetus to continue posting finding aids for marketing purposes.

One of the interesting outcomes of this study involves Google+. At first, Google+ was headed for the dustbin. With little user interest and only five clickthroughs, the platform seemed a bad fit for marketing finding aids. However, Google+ posts seem to have great staying power on the first page of search results on Google. Admittedly, a Google product producing robust search results is not overly surprising. The extent to which Google+ is affecting Google's search algorithm compared to other social media platforms seems a worthy question for future research. ${ }^{33}$ 


\section{Social Media Success}

After a year of social media efforts, awareness of SHSU Special Collections has increased within both the local and campus communities. More students, faculty, and local community members are contacting the archives for research help. Notably, a researcher traveled four hours to use three large manuscript collections. When the special collections librarian asked him how he found these collections, he admitted to reading all about them on WordPress. A master's student in history, the patron was unfamiliar with finding aids, however, and was unable to navigate one. He had never clicked-through to a finding aid from the WordPress posts. This reveals a potential user behavior in that those unfamiliar with finding aids might read posts and simply not click-through due to a lack of familiarity. While in-house reference interactions were not a focus of this study, this interaction was informative to the research team. While anecdotal, it reveals that some researchers might visit SHSU Special Collections or access online collection materials because of a general awareness of the collection rather than a specific interaction with a finding aid.

Since the end of the research phase in December 2013, the digital resources librarian has maintained all ten social media platforms in anticipation of further research. Additionally, the digital resources librarian continues to engage with users by following their accounts, liking posts, and reblogging their materials. Since the research phase ceased, SHSU's Tumblr and WordPress accounts have experienced massive growth. The Tumblr site was a trending blog twice and appeared on Tumblr Radar three times. At the end of the research phase in December 2013, the SHSU Tumblr site had 146 followers and 8,034 followers as of September 2014. The WordPress blog went from 172 followers in December 2013 to 5,707 as of September 2014. The Twitter and Pinterest accounts also have more followers. While building followers was not a specific goal of the research phase, the efforts undertaken during the build up to the research phase and during the research phase did enhance the quality and quantity of online interaction (and the number of followers).

SHSU Special Collections plans to maintain WordPress and Tumblr sites and contribute to the shared SHSU Library Facebook and Twitter accounts. According to the research findings, this is the best recipe for success in marketing finding aids on social media. While Google+ did not produce the clickthrough results the researchers would have liked, it does have potential for increasing general outreach since Google+ posts appear higher in Google search results. The research team will therefore maintain the Google+ site for the time being as staff time allows. 


\section{Conclusion}

In libraries and archives, daily work can be summarized as solving problems using the best information available. The research team believes that this research project provides a solution to an essential problem facing archives, namely, how to promote and market finding aids and the collections they represent in an increasingly congested information environment. The heart of archival work is arranging and describing collections, but if people do not access these collections, the effort seems ill spent. After three months tracking every click-through from ten social media sites, this study indicates that a combination of WordPress, Facebook, and Twitter provides the best marketing strategy for getting the word out about finding aids. With WordPress blog posts and modified posts to Facebook and Twitter, archivists could, with relative ease and within the time constraints we all face, promote finding aids on social media and get a solid ROI.

\section{Notes}

1 Society of American Archivists, Describing Archives: A Content Standard, 2nd ed. (Chicago: Society of American Archivists, 2013).

2 About, Archon, http://archon.org/about.php.

3 For a more extensive background into Archon, including a functional and technical description, see Scott W. Schwartz, Christopher Prom, Kyle Fox, and Paul Sorensen, "Archon: Facilitating Global Access to Collections in Small Archives," IFLA Conference Proceedings (2008), http://citeseerx.ist .psu.edu/viewdoc/download?doi=10.1.1.150.6658\&rep=rep1\&type=pdf. Other sources for Archon include Benjamin Bromley, "Going Digital: Open-Source Access Tools and the SCRC," Virginia Libraries (January-March 2012); William Jordan Patty, "Metadata, Technology, and Processing a Backlog in a University Special Collections," Journal of Archival Organizations 6, nos. 1-2 (2008); Dennis Meissner and Mark A. Greene, "More Application while Less Appreciation: The Adopters and Antagonists of MPLP," Journal of Archival Organization 8, nos. 3-4 (2010); Marianne Swierenga, "Shedding Light on Hidden Collections," Gatherings Newsletter, Western Michigan University, http://scholarworks.wmich.edu/cgi/viewcontent.cgi?article=1216\&context= gatherings; Christopher J. Prom, Christopher A. Rishel, and Scott W. Schwartz, "A Unified Platform for Archival Description and Access," Proceedings of the 7th ACM/EEE Joint Conference on Digital Libraries, JCDL 2007: Building and Sustaining the Digital Environment, 157-66; J. Gordon Daines III and Cory L. Nimer, "Re-Imagining Archival Display: Creating User-friendly Finding Aids," Journal of Archival Organization 9, no. 1 (2011); and Thomas J. Frusciano. “Ten Years After”: The Next Wave of EAD Implementation," Journal of Archival Organization 5, no. 3 (2008).

4 Sean Heyliger, Julie McLoone, and Nikki Lynn Thomas, "Making Connections: A Survey of Special Collections' Social Media Outreach,” The American Archivist 76, no. 2 (2013): 379-81.

5 For examples in the business literature, see Richard Hanna, Andrew Rohm, and Victoria L. Crittenden, "We're All Connected: The Power of the Social Media Ecosystem," Business Horizons 54 (2011); Andreas M. Kaplan and Michael Haenlein, "Users of the World, Unite! The Challenges and Opportunities of Social Media," Business Horizons 53 (2010); W. Glynn Mangold and David J. Faulds, "Social Media: The New Hybrid Element of the Promotion Mix," Business Horizons 52 (2009). Examples in the library and archival literature include Ligaya Ganster and Brigget Schumacher, "Expanding beyond Our Library Walls: Building an Active Online Community through Facebook," Journal of Web Librarianship 3 (2009); Nuria Lloret Romero, "ROI. Measuring the Social Media Return on Investment in a Library," The Bottom Line: Managing Library Finances 24, no. 2 (2011); Helene Blowers, "Measuring Social Media and the Greater Digital Landscape," Computers in Libraries 32, no. 
7 (2012); Bruce Washburn, Ellen Eckert, and Merrilee Proffitt, “Social Media and Archives: A Survey of Archive Users” (Dublin, Ohio: OCLC Research, 2013), http://www.oclc.org/content/dam/research/ publications/library/2013/2013-06.pdf; and Kate Theimer, "What Is the Meaning of Archives 2.0?," The American Archivist 74, no. 1 (2011).

6 Susanna R. Campbell, Ismet Anitsal, and M. Meral Anitsal, “Social Media’s Key Success Factors: An Analysis of Customer Reactions,” Business Studies Journal 5, no. 1 (2013): 50.

7 Campbell et al., "Social Media’s Key Success Factors,” 54.

8 Campbell et al., "Social Media’s Key Success Factors,” 51.

9 Campbell et al., “Social Media’s Key Success Factors,” 52.

${ }^{10}$ Heyliger et al., "Making Connections: A Survey of Special Collections' Social Media Outreach,” 390.

${ }^{11}$ Heyliger et al., "Making Connections: A Survey of Special Collections' Social Media Outreach,” 391.

${ }^{12}$ Yosra Akrimi and Romdhane Khemakhem, "What Drives Consumers to Spread the Word in Social Media?," Journal of Marketing Research and Case Studies (2012): 2-9.

${ }^{13}$ Shakeel Ahmad Khan and Rubina Bhatti, "Application of Social Media in Marketing of Library and Information Services: A Case Study from Pakistan,” Webology 9, no. 1 (2012), http://www.webology .org/2012/v9n1/a93.html.

${ }^{14}$ Lili Luo, Yuan Wang, and Lifeng Han, "Marketing via Social Media: A Case Study," Library Hi Tech 31, no. 2 (2013): 455, 464.

${ }^{15}$ Selene Colburn and Laura Haines, "Measuring Libraries' Use of YouTube as a Promotional Tool: An Exploratory Study and Proposed Best Practices,” Journal of Web Librarianship 6 (2012): 25-27.

${ }^{16}$ Dianna E. Sachs, Edward J. Ecket, and Kathleen A. Langan, "Striking a Balance: Effective Use of Facebook in an Academic Library,” Internet Reference Services Quarterly 16 (2011): 46-48.

${ }^{17}$ Mira Foster, Hesper Wilson, Nicole Allensworth, and Diane T. Sands, "Marketing Research Guides: An Online Experiment with LibGuides,” Journal of Library Administration 50 (2010): 610-11.

${ }^{18}$ Adam Crymble, "An Analysis of Twitter and Facebook Use by the Archival Community," Archivaria 70 (2010): 146.

${ }^{19}$ Melanie Griffin and Tomaro I. Taylor, "Of Fans, Friends, and Followers: Methods for Assessing Social Media Outreach in Special Collections Repositories,” Journal of Web Librarianship 7, no. 2 (2013): 268.

${ }^{20}$ Alexa, "About Us," http://www.alexa.com/about.

21 "Pinterest for Cultural Heritage," Archives Info, http://archivesinfo.blogspot.com/2012/02/pinterestfor-cultural-heritage.html.

${ }^{22}$ As of January 2013. These figures came from emails from the Archives and Archivist listserv administrator and Arkansas History listserv administrator.

${ }^{23}$ Through an error, a tracking URL was left off the posts to the listservs. The research team was able to isolate the results from those posts via other traffic and was able to track resulting clickthroughs using Google Analytics. Both posts should have contained a tracking URL for both a collection and the Archon page proper. The collection tracking URL was included, while the Archon page proper URL was left off. However, Google Analytics was tracking click-throughs to Archon in a separate information data set.

${ }^{24}$ Kate Tkacik, “Tumblrarian 101: Tumblr for Libraries and Librarians,” The Digital Shift, August 27, 2012, http://www.thedigitalshift.com/2012/08/social-media/tumblrarian-101-tumblr-for-libraries-andlibrarians/.

${ }^{25}$ For an example of a miniature book GIF, visit SHSU Special Collections and University Archives, http://nglspecialcollectionsandarchives.tumblr.com/post/60773527021/painted-fans-of-japancheck-out-this-miniature.

${ }^{26}$ For an example of an animated GIF, visit SHSU Special Collections and University Archives, http:// nglspecialcollectionsandarchives.tumblr.com/post/65616683810/cover-of-wild-dog-13-the-coversof-wild-dog.

27 “Justin Timberlake Tries to Bring Myspace Back," CBS News, September 26, 2012, http://www .cbsnews.com/news/justin-timberlake-tries-to-bring-myspace-back/.

28 “Top 15 Most Popular Social Networking Sites,” eBiz: MBA Guide, http://www.ebizmba.com/articles/ social-networking-websites. 
${ }^{29}$ Steve Rayson, “10 Ways Google+ Will Improve Your SEO,” Social Media Today, July 17, 2013, http:// socialmediatoday.com/steve-rayson/1600736/ten-ways-google-plus-will-improve-your-seo.

30 “Top Pins from 2013,” Pinterest Blog, December 19, 2013, http://blog.pinterest.com/post/70483937511/ top-pins-from-2013.

${ }^{31}$ Flickr and LinkedIn were omitted from Figure 6 because both sites have a large community, but potential click-throughs were often coming from the general audience, not specific followers. The research team was able to differentiate followers from general audience and pull out specific figures for all platforms represented in this chart. This differentiation was not possible for Flickr and LinkedIn, so both platforms were excluded here.

32 Jessica Lee, "No. 1 Position in Google Gets 33 \% of Search Traffic," Search Engine Watch, June 20, 2013, http://searchenginewatch.com/article/2276184/No.-1-Position-in-Google-Gets-33-of-SearchTraffic-Study.

${ }^{33}$ According to Rayson, "10 Ways Google+ Will Improve Your SEO," "There are still people that argue for a wait and see strategy before using Google+. They will often point to lower numbers of people using Google+. These people fundamentally misunderstand the nature of Google+ and the way it can improve your SEO results, even if none of your clients actually use Google+ itself."

\section{ABOUT THE AUTHORS}

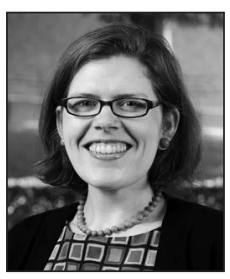

Felicia Williamson is the outgoing head of special collections at Sam Houston State University where she has implemented a full processing, description, and outreach program. Williamson will become the archivist at the Dallas Holocaust Museum beginning this fall. Williamson is the outgoing chair of the Professional Development Committee, Society of Southwest Archivists, and has been a certified archivist since 2011.

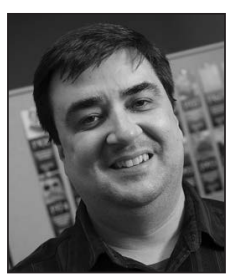

Scott Vieira is the electronic resources librarian at Rice University. He has worked in both public and academic libraries. Vieira's experience includes public services, community partnerships, collection development for a special collection, and technology consultation. Vieira is also a reviewer for Library Journal on subjects including human sexuality, the neurosciences, science and religion, and graphic novels.

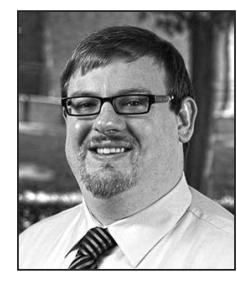

James Williamson is the outgoing digital resources librarian at Sam Houston State University where he was responsible for managing all digitized and born-digital collections within the library. Williamson will be joining the staff at SMU in Dallas working as a digital production librarian beginning this fall. Williamson is a certified archivist and digital archives specialist, and chair of the Membership Committee, Society of Southwest Archivists. 